\title{
Zafar, Samra (with Meg Masters). (2019). A Good Wife: Escaping the Life I Never Chose: A Memoir. Toronto: Harper Collins.
}

\author{
Reviewed by: Huda Asad, MacEwan University
}

Samra Zafar's book, "A Good Wife" is a memoir detailing her struggles and hopes of attaining higher education while enduring an abusive marriage because of familial and cultural pressures. This memoir outlines Zafar's experiences of abuse through both her childhood and her adult life. This book review will focus on how religion, societal and cultural norms, and abuse can be negatively used to force women in staying in abusive marriages.

Often times, Samra's identity as a Muslim woman is controlled by her in-laws and Ahmed. She lives in constant fear of being caught interacting with Canadians and is subjected to physical or verbal discipline if non-compliant. Samra's husband enforces his views by saying, "Don't try to make friends. Canadian people are so corrupt. They will make you un-muslim” (p. 259). This false narrative of being considered "un-muslim" when socializing with others is used to isolate her and prevent her from being corrupted by the Western ideology of freedom. Even though she initially tried to ignore Ahmed's hurtful taunts, his words deeply affected Samra even when he was not around. The insults result in her trying best to avoid unnecessary social interactions as it could put her "schooling in jeopardy" (p. 260).

Quranic verses are used out of context to normalize and validate the abuse in order to make 
Samra lose her sense of agency. Amma views abuse as being "perfectly permissible in Islam for a man to hit his wife. It's written in the Koran. And other woman have it much worse than you do, but they still stay" (p. 63). Amma enforces that the abuse is needed to make her be a good wife and justifies it using the Quran. She makes it difficult for Samra to leave her marriage as she is guilt tripped into believing abuse is normal and is made to feel ashamed about her reaction. Zafar is often criticized with passive-aggressive insults about not being a good, Muslim wife by her husband and in-laws by picking and choosing which verses they want to follow to their advantage. Many passages in the Quran are distorted to fit their ideologies and are used on Samra as a way to gain control of her life. Samra's in laws and husband justify their mistreatment of her using religion; they are able to facilitate power and control over her by limiting her social interactions and opportunities to further isolate her.

Money is used as a way to make Samra dependent on her husband and to guarantee complete compliance. By preventing Samra from working, her husband and in-laws are able to gain power and control while keeping her submissive. When ever Samra was in need of money, she was told to "get lost" as her husband had "no money to waste" (p. 148). Through manipulation, Samra is made to feel like she is a burden and feels unsure of herself due to the financial and emotional abuse she endures. Due to her not being financially stable yet, she is unable to buy necessities and would often find herself asking for money. Samra is made to feel like the necessities she is asking for are way out of reason resulting in her husband resorting to verbal and physical abuse; "You think I have money to throw around? You're such a useless whore! Why haven't you trained her already" (p. 162). Amma uses Aisha as a way to control Samra and to 
terrify her from leaving. If she ever leaves, "the government would give Aisha to Ahmed" since she has "no education and no money" (pp. 152-153). Since Samra lacks an education and is unable to financially provide for her and Aisha, she feels as she has no other choice but to stay. Without no means to support herself and no real access to money, Samra is left vulnerable to physical abuse and violence. She has extreme difficulty protecting herself and Aisha while struggling to put herself first as she is made to believe that life is supposed to be this way and it is her "duty to stay quiet" (p. 153).

Due to necessity, Samra is allowed to work after her husband reluctantly agrees that it is for the greater good. Even though Samra has to work in order to relieve some financial tensions, her in-laws automatically believe any work that is unrelated to the house is "a sort of prostitution" and a disgrace to them (p. 179). I found it discouraging how Samra's in-laws degraded her and her job instead of being happy for her and congratulating her for her first job. As her in-laws, I would expect them to feel proud of her and be relieved for their son as he was financially struggling. They showed no effort to hide how they really felt as their reaction shows that they do not want women to be working out of the house even if needed. Even at work, Samra has to manage her "interactions with the customers--- especially the male ones" as she is often accused of enjoying "talking to other men" and flirting (p. 182). The effects of these accusations are shown when Samra has to be careful even at work to not talk to men as it might upset her husband.

Societal and culture pressures play an important role in Zafar's life. Growing up as a South Asian woman, she was often subjected to cultural and gender roles. Even though her father encouraged her to chase her dreams and to have a higher education, she still felt like she had to get 
married at a young age due to cultural and societal pressures. When Samra began to have doubts as to if she was denying her "best chance to go to school abroad", she called Ahmed for reassurance resulting in her agreeing to marriage (p. 61). Samra felt in order to succeed, she had to convince herself that marriage was the best option for her education and that she was doing herself a disservice by not being grateful for a marriage proposal. Due to culture, Samra is expected to know how to cook and clean while taking care of her husband and in-laws even when pregnant. The idea of women existing for the sole purpose of marriage, child bearing, and housework is simply degrading and is often used against Samra.

Even if Zafar tried her best to keep her husband happy, she would be still met with different ways she has embarrassed him. During a dinner party, she hugged her woman friend's goodbye and was instead met with insults thrown at her by her husband. Even though it was a friendly hug, she was accused of "being a whore" and was slapped (p. 253). He even goes to the extent of humiliating Samra by emphasizing that she is nothing but "property" to him when he says, "I don't care what other women do. They aren't my property. I don't want other men to look at my property. It's your job to protect my honour" (p. 253). Samra is often dictated by him as to what she is allowed and not allowed to do and has to follow her husband's restrictive measures to prove her loyalty and to not give him a chance to abuse her.

Through her mentors and peers at University of Toronto, she is able to leave her abuser and start a new life with her children without feeling guilty. During her session with her councillor, she begins to realize that she is being abused and that the only way to stop the cycle would be for 
Ahmed to understand that his "behaviour needs to change" (p. 271). With this knowledge, Samra is able to defend herself from his abuse and knows that she should not be treated in this abusive manner. Zafar emphasizes the need for a "sense of belonging" within a community and how important it is to be there for survivors (p. 378).

Samra Zafar's memoir is an extremely engaging and interesting book that sheds light on domestic violence and how difficult it can be to leave. This memoir would be extremely useful for disciplines like social work, sociology, and psychology with a focus on family dynamics. I would recommend this memoir for personal enjoyment and to anyone who is going through an abusive relationship in hopes of empowering them. 